\title{
Orthodontic management of traumatized teeth: a literature review
}

\section{Sara Ahmed Hifny ${ }^{1 *}$, Mohammed Abdulrazzag Hawsawi ${ }^{2}$, Abdulaziz Mohammed Baraat ${ }^{3}$, Wesam Faiz Bakhadlaq ${ }^{4}$, Hafiz Mohammed Hakami ${ }^{5}$, Abdullah Abdulghani Alghamdi ${ }^{6}$, Homood Mohammed Alsayegh ${ }^{7}$, Asmaa Tariq Ashour ${ }^{8}$, Ahmed Abdullah Bahamid", Rehan Salem Alsalem ${ }^{10}$, Shereen Osama Jiffri ${ }^{11}$}

\author{
${ }^{1}$ Dental Surgery Department, Andalusia Hospitals, Jeddah, Saudi Arabia \\ ${ }^{2}$ General Dentist, Ministry of Health, Jeddah, Saudi Arabia \\ ${ }^{3}$ General Dentist, Dammam Medical Complex, Dammam, Saudi Arabia \\ ${ }^{4}$ General Dentist, Ministry of Health, Mecca, Saudi Arabia \\ ${ }^{5}$ College of Dentistry, King Khalid University, Abha, Saudi Arabia \\ ${ }^{6}$ General dentist, Ministry of health, Prince Mishari bin Saud Hospital, Baljurashi, Saudi Arabia \\ ${ }^{7}$ Department of Maxillofacial Surgery, King Abdulaziz Hospital, Jeddah, Saudi Arabia \\ ${ }^{8}$ Ministry of Health, Medina, Saudi Arabia \\ ${ }^{9}$ College of Dentistry, Riyadh Elm University, Riyadh, Saudi Arabia \\ ${ }^{10}$ College of Dentistry, Majmaah University, Zulfi, Saudi Arabia \\ ${ }^{11}$ General dentist, King Abdulaziz Dental Hospital, Jeddah, Saudi Arabia
}

Received: 01 May 2021

Accepted: 17 May 2021

*Correspondence:

Dr. Sara Ahmed Hifny,

E-mail: sara.hifny@ hotmail.com

Copyright: (c) the author(s), publisher and licensee Medip Academy. This is an open-access article distributed under the terms of the Creative Commons Attribution Non-Commercial License, which permits unrestricted non-commercial use, distribution, and reproduction in any medium, provided the original work is properly cited.

\begin{abstract}
Traumatic dental injuries can significantly impact the appearance and the functions of the affected teeth and can induce significant damages to the surrounding structures within the oral cavity including both the soft and hard ones. This present literature review aimed to discuss the appropriate orthodontic management of dental traumatic events and to present evidence from previous studies in the literature. The search took place in the relevant databases 1 , such as PubMed, Web of Science, Scopus and Google Scholar to find the relevant articles that have previously discussed the topic to retrieve all the potentially related information that will help to formulate strong evidence. The literature review was focused on the orthodontic management considerations for patients that had dental traumas including crown and crown-root fractures, in addition to intrusion and extrusion luxation injuries. Overall, orthodontists should be able to deal with all the possible traumatic lesions as early as possible to avoid the development of any complications which might affect the prognosis of the affected teeth and the surrounding structures. Moreover, the evidence suggested that aforementioned lesions which was a period of at least three months should be recommended after applying the orthodontic treatment to early screen against any potential complications and maintain stabilization.
\end{abstract}

Keywords: Orthodontics, Dental management, Trauma

\section{INTRODUCTION}

Traumatic dental injuries can significantly impact the appearance and the functions of the affected teeth and can induce significant damages to the surrounding structures within the oral cavity including both the soft and hard ones. The etiology of dental injuries includes a variety of causes and events such as fierce sporting practices, accidents, falls, fights and other activities that might need surgical approaches. ${ }^{1,2}$ Moreover, the occurrence of dental injuries is recently becoming more common among orthodontic patients. Therefore, many recommendations 
have been declared to guide orthodontists to apply the right and the appropriate management and to enhance the prognosis of both the affected teeth and the orthodontics of the affected patient by applying the modality to avoid any further complications. Accordingly, multidisciplinary orthodontists play a major role in such activities to inaugurate proper management plans for these events. ${ }^{3}$

Many risk factors can attribute to having a traumatic dental injury. Also, some groups are more affected than others such factors might include the reduced length of the upper lip or incompetent lips lengths. ${ }^{4-7}$ The orthodontic management of dental traumatic injuries might not be suitable for every patient and no standards have been reported in the literature. Therefore, orthodontists usually manage each case alone with no standardization for the management modality. However, the management modality can be applied based on the different factors such as the anatomy of the trauma, the health condition of the patient and the presence of other co-morbidities which might interfere with the modality, chronicity and severity of the injury. In addition, the presence of any related devices that might also interfere with the management plan. Planning whether orthodontic force should be applied or not is also another important factor when assigning the appropriate management plan. Root resorption can result from the administration of heavy force that might also cause other adverse events. ${ }^{8,9}$

Besides, having a previous orthodontic treatment is a risk factor for the potential development of teeth trauma in these patients. Although such cases have been previously reported in the literature, no concise guidelines were also found for the appropriate management of these cases and the treatment is usually based on the experience and the skills of the orthodontists. ${ }^{3,10,11}$ Accordingly, the experience and the skills of these dentists are two important factors for conducting the appropriate management modalities in cases when urgent approaches might be needed to enhance the prognosis. ${ }^{12}$ Moreover, researching these events to shed more light on the proper management and the interventions which is also play an important part in drawing unified and specific guidelines. This present literature review aimed to discuss the appropriate orthodontic management of dental traumatic events and to present evidence from previous studies in the literature.

\section{METHODOLOGY}

A systematic search was conducted to identify relevant studies in the following databases like PubMed, Medline, Web of Science, Embase, Google Scholar and Scopus. The following search terms were used (orthodontic), (management) and (trauma). The reference lists were manually searched to identify additional relevant studies meeting inclusion criteria. We included any study that reports orthodontic management of dental trauma. No restrictions were applied.

\section{DISCUSSION}

\section{Crown and crown-root fractures}

Evidence from previous studies has showed that crown fractures might constitute up to one to three fourth of the possible dental traumatic injuries and can ultimately lead to delayed or absent of permanent dentition. ${ }^{13,14}$ Crown fractures can be mainly divided into complicated and non-complicated fractures and traumas which are based on the involvement of the pulp of the affected tooth. Moreover, previous studies have demonstrated that uncomplicated dental crown fractures are the most frequently reported in dental clinics as they constitute a total of $50 \%$ of the estimated dental fractures. ${ }^{15,16}$ In cases of uncomplicated crown fractures, it has been reported that the tooth enamel and the dentin might be involved and impacted. Accordingly, specific radiological examinations should be conducted to adequately detect the lesion to plan the best orthodontic management modality that does not interfere with this trauma.

Orthodontics can inaugurate the management modality following the trauma that occurred by three months unless related complications were observed. Moreover, after this period, if suspicion of complications was present, further notice is recommended. Besides, it has been previously recommended that the orthodontics movement should be initiated in patients who have been observed to avoid having a complete root development and even before the development of the affected retained root. ${ }^{17}$ On the other hand, complicated crown fractures might need special approaches. For instance, capping for the affected pulp from the traumatized tooth is recommended to cover the soft tissue of the affected pulp that is usually exposed and can lead to some complications. ${ }^{17}$ Moreover, the orthodontic movement of the affected crowns is not recommended until the adequate appearance of the hard capping of the affected pulp has been designed to protect the pulp tissue. Previous investigations recommended radiological follow-up. The pulp vitality should be tested for at least three consecutive months from the capping. Moreover, it has been recommended that follow-up should be conducted for these patients after being orthodontically treated at six months and after one and two years. ${ }^{17}$

Crown-root fractures can be identified as traumatic injuries that involve the dentin, enamel or cementum. They are also divided into complicated and noncomplicated fractures as crown fractures. The prevalence of crown-root traumas has been estimated to be $5 \%$ only among other dental fractures. ${ }^{18,19}$ A partial pulpectomy is usually recommended for complicated cases, while other orthodontic procedures are usually performed like complicated crown fractures. For tooth restoration, previous investigations have suggested that the fracture line should be extended to a supra-gingival level. Extrusion was first introduced in 1973 and was then modified and reported by many clinicians and orthodontic 
experts. ${ }^{20}$ Moreover, it is recommended that endodontic approaches should be applied to the affected teeth before initiating the orthodontic management of modality and extrusion, which is then performed to adjust the coronal fracture line without any modifications to the bone line coronal margins, which will reduce any potential requirement to reshape the underlying bones. It has been previously estimated that it takes around one month to extrude 3-4 millimeters of one affected tooth. Fibrotomy can then be performed to obtain retention by a month approximately and to intervene against the occurrence of relapses. ${ }^{17}$ Finally, previous investigations in the literature have reported that root resorptions are rare to be observed in these types of fractures. ${ }^{21-23}$

\section{Subluxation and concussion}

A subluxation can be identified as a trauma affecting the surrounding and supporting structures of the tooth, which might result in the pathological loosening of the relevant tooth within its socket. Previous studies have demonstrated that the frequency of subluxation can contribute to $21 \%$ of the total dental traumatic injuries. $^{24,25}$ Moreover, secondary complications might also occur which may affect the prognosis of the affected sockets and relevant teeth. Such complications might be attributable to infections, inflammation, repair or replacement-related and loss of the tooth or marginal bone. Moreover, it has been reported that splinting might not be required for the affected parts unless multiple traumas were observed. ${ }^{17}$ Additionally, this type of trauma is less frequent and less severe than other forms of injuries. A duration of three consecutive months of follow-up has been previously recommended before resuming the orthodontic management plan. ${ }^{3,26,27}$

In the same context, a concussion can be mixed with subluxation of the affected tooth. However, it has been found that a concussion is not usually associated with displacement or movement of the relevant tooth where the injury took place. Moreover, within the periodontal area and ligaments, some inflammation and edema can be observed. Tenderness over the affected area can be also noticed. However, bleeding is not frequently seen. The prevalence of concussion among other traumatic dental injuries has been found to constitute around $23 \% .{ }^{24,25}$ As subluxation, a three month follow-up period is recommended before starting the orthodontic management to properly intervene against any potential complications. $^{3,26,27}$

\section{Intrusion and extrusion luxation}

Previous research has demonstrated that the extrusvie dental traumas are usually accounted for $7 \%$ of the total dental traumas that affect the permanent teeth and are known as the presence of an incomplete displacement of the affected tooth from its socket. ${ }^{25}$ The initial management of these events is to restore the right position of the affected tooth to its socket using a flexible splint and wait for at least two weeks for stabilization. If this step was not done as early as possible, the process of extrusion might become so difficult. As a result, the formation of clots makes it even more difficult to conduct the orthodontic treatment. ${ }^{28,29}$ Nevertheless, pulp necrosis has also been frequently reported following this type of traumatic dental injury and the development of necrosis is a potent indicator for root canal modification and management. ${ }^{28-30}$ For extrusive laxative traumatic dental injuries of permanent teeth that exceed two millimeters, laser management has been previously introduced as an efficacious modality that can effectively replace the endodontic management modalities. ${ }^{31}$ Delayed or ignored early repositioning of the affected teeth might lead to the development of serious complications leading to reduced crown to root ratio and decreased support of the surrounding bony structures. Moreover, this will even make it harder for orthodontists to draw the appropriate management modality of this trauma. ${ }^{32}$ Apart from applying orthodontic intrusive treatment modalities, reshaping of the crown to root ratio has been previously recommended as a substitution. Intentional replantation has also been previously described as an efficacious approach, however, it should not be used in cases where any underlying dental diseases or complications were already present. ${ }^{32-34}$ A follow-up period of three to six months is recommended after applying the orthodontic treatment to adequately make sure no adverse events will develop following the trauma. ${ }^{3,17}$

Intrusion luxation type of dental traumatic injuries that is usually associated with impeding of the affected tooth into the underlying alveolar bone and can be complicated by potential fractures within the affected region. It has been previously noticed that such lesions affect the frontal maxillary teeth are more frequently than in other locations. ${ }^{35-37}$ Moreover, it does not frequently occur in the permanent teeth as compared to the primary dentition period. Therefore, it can induce serious complications such as inflammation and necrosis of the relevant pulp and root, in addition to a potential loss in the marginal relevant bone. ${ }^{17}$ The treatment of these types of injuries is variable and mainly depends on the maturity of the root of the apex of the affected tooth. Previous investigations have recommended that immature teeth should be observed for eruption as intrusions are not usually harmful and severe. ${ }^{38-40}$

However, interventions should be considered when eruption does not spontaneously occur or when intrusion is severe and can lead to serious complications. Affected mature teeth should be managed early, within the first few weeks following the lesion, by repositioning to prevent any potential pulp necrosis. ${ }^{41,42}$ If bone fractures were noticed, surgical interventions are recommended for the appropriate repositioning of the affected parts. ${ }^{43}$ It should also be noted that ankylosis of the affected tooth can result from applying a heavy orthodontic force for the management of luxation. ${ }^{44,45}$ Long-term follow-up of applying orthodontic traction is also recommended and 
can be an effective modality for managing ankylosed cases. ${ }^{46-48}$

\section{CONCLUSION}

Traumatic injuries affecting the teeth are frequently seen globally and are observed to affect the different population groups including children, adolescents and adults. Orthodontists should be able to deal with all the possible traumatic lesions as early as possible to avoid the development of any complications which might affect the prognosis of the affected teeth and the surrounding structures. Moreover, as evidence suggests for the aforementioned lesions, a period of three months at least should be recommended after applying the orthodontic treatment to early screen against any potential complications and to maintain stabilization.

\section{Funding: No funding sources Conflict of interest: None declared \\ Ethical approval: Not required}

\section{REFERENCES}

1. Glendor U. Epidemiology of traumatic dental injuries-a 12 year review of the literature. Dental Traumatol. 2008;24(6):603-11.

2. Lam R. Epidemiology and outcomes of traumatic dental injuries: a review of the literature. Aust Dent J. 2016;61(1):4-20.

3. Kindelan SA, Day PF, Kindelan JD, Spencer JR, Duggal MS. Dental trauma: an overview of its influence on the management of orthodontic treatment. Part 1. J Orthodon. 2008;35(2):68-78.

4. O'Mullane DM. Some factors predisposing to injuries of permanent incisors in school children. Brit Dent J. 1973;134(8):328-32.

5. Chaturvedi R, Kumar A, Rana V, Aggarwal A, Chandra L. A correlation of permanent anterior tooth fracture with type of occlusion and craniofacial morphology. Int $\mathrm{J}$ Clin Pediatr Dent. 2013;6(2):80-4.

6. Bauss O, Röhling J, Schwestka-Polly R. Prevalence of traumatic injuries to the permanent incisors in candidates for orthodontic treatment. Dental Traumatol. 2004;20(2):61-6.

7. Brin I, Ben-Bassat Y, Heling I, Brezniak N. Profile of an orthodontic patient at risk of dental trauma. Dental Traumatol. 2000;16(3):111-5.

8. Schwartz-Arad D, Levin L, Ashkenazi M. Treatment options of untreatable traumatized anterior maxillary teeth for future use of dental implantation. Implant Dentist. 2004;13(2):120-8.

9. Poi WR, Cardoso-Lde C, deCastro JC, Cintra LT, Gulinelli JL, deLazari JA. Multidisciplinary treatment approach for crown fracture and crownroot fracture - a case report. Dental Traumatol. 2007;23(1):51-5.

10. Owtad P, Shastry S, Papademetriou M, Park JH. Management guidelines for traumatically injured teeth during orthodontic treatment. J Clinic Pediat Dentist. 2015;39(3):292-6.

11. Bauss O, Röhling J, Meyer K, Kiliaridis S. Pulp vitality in teeth suffering trauma during orthodontic therapy. Angle Orthodon. 2009;79(1):166-71.

12. al-Nazhan S, Andreasen JO, al-Bawardi S, al-Rouq $\mathrm{S}$. Evaluation of the effect of delayed management of traumatized permanent teeth. $\mathrm{J}$ Endod. 1995;21(7):391-3.

13. Andreasen JO, Ravn JJ. Epidemiology of traumatic dental injuries to primary and permanent teeth in a Danish population sample. Int $\mathrm{J}$ Oral Surg. 1972;1(5):235-9.

14. Noori AJ, Al-Obaidi WA. Traumatic dental injuries among primary school children in Sulaimani city, Iraq. Dent Traumatol. 2009;25(4):442-6.

15. Saroğlu I, Sönmez H. The prevalence of traumatic injuries treated in the pedodontic clinic of Ankara University, Turkey, for 18 months. Dent Traumatol. 2002;18(6):299-303.

16. Vanka A, Ravi KS, Roshan NM, Shashikiran ND. Analysis of reporting pattern in children aged 7 to 14 years with traumatic injuries to permanent teeth. Int J Clin Pediatr Dent. 2010;3(1):15-9.

17. Jaradat M, Rahhal A. Orthodontic considerations for traumatized permanent teeth. Brit J Med Res. 2016;15:1-8.

18. Andreasen JO. Etiology and pathogenesis of traumatic dental injuries. A clinical study of 1,298 cases. Scandina J Dent Res. 1970;78(4):329-42.

19. Andersson L. Epidemiology of traumatic dental injuries. Journal of endodontics. 2013;39(3):S2-5.

20. Heithersay GS. Combined endodontic-orthodontic treatment of transverse root fractures in the region of the alveolar crest. Oral Surg Oral Med Oral Pathol. 1973;36(3):404-15.

21. Kahnberg KE. Surgical extrusion of root-fractured teeth-a follow-up study of two surgical methods. Endod Dent Traumatol. 1988;4(2):85-9.

22. Das B, Muthu MS. Surgical extrusion as a treatment option for crown-root fracture in permanent anterior teeth: a systematic review. Dent Traumatol. 2013;29(6):423-31.

23. Elkhadem A, Mickan S, Richards D. Adverse events of surgical extrusion in treatment for crown-root and cervical root fractures: a systematic review of case series/reports. Dent Traumatol. 2014;30(1):1-14.

24. Scheer B. Traumatic dental injuries-a manual. 2nd edition). Brit Dent J. 2004;196(3):182.

25. Borum MK, Andreasen JO. Therapeutic and economic implications of traumatic dental injuries in Denmark: an estimate based on 7549 patients treated at a major trauma centre. Int $\mathbf{J}$ Paediat Dent. 2001;11(4):249-58.

26. Hermann NV, Lauridsen E, Ahrensburg SS, Gerds TA, Andreasen JO. Periodontal healing complications following concussion and subluxation injuries in the permanent dentition: a longitudinal cohort study. Dent Traumatol. 2012;28(5):386-93. 
27. Curtis Jr JW, McLain JB, Hutchinson RA. The incidence and severity of complications and pain following periodontal surgery. J Periodontol. 1985;56(10):597-601.

28. Diangelis AJ, Andreasen JO, Ebeleseder KA, Kenny DJ, Trope M, Sigurdsson A, et al. International association of dental traumatology guidelines for the management of traumatic dental injuries: 1 . fractures and luxations of permanent teeth. Dent Traumatol. 2012;28(1):2-12.

29. Diangelis AJ, Andreasen JO, Ebeleseder KA, Kenny DJ, Trope M, Sigurdsson A, et al. Guidelines for the management of traumatic dental injuries: 1 . fractures and luxations of permanent teeth. Pediatr Dent. 2017;39(6):401-11.

30. Dumsha T, Hovland EJ. Pulpal prognosis following extrusive luxation injuries in permanent teeth with closed apexes. J Endod. 1982;8(9):410-2.

31. Görür I, Orhan K, Can-Karabulut DC, Orhan AI, Oztürk A. Low-level laser therapy effects in traumatized permanent teeth with extrusive luxation in an orthodontic patient. Angle Orthod. 2010;80(5):968-74.

32. Proffit WR, Fields HW, Sarver DM. Contemporary Orthodontics. 6th ed. Canada: Elsevier Health Sciences; 2006.

33. Martins WD, Westphalen VP, Perin CP, DaSilva Neto UX, Westphalen FH. Treatment of extrusive luxation by intentional replantation. Int $\mathrm{J}$ Paediat Dent. 2007;17(2):134-8.

34. Hamanaka EF, Nogueira LM, Pires WR, Panzarini SR, Poi WR, Sonoda CK. Replantation as treatment for extrusive luxation. Brazil Dent J. 2015;26(3):308-11.

35. Andreasen JO. Luxation of permanent teeth due to trauma. A clinical and radiographic follow-up study of 189 injured teeth. Scandin J Dent Res. 1970;78(3):273-86.

36. Spinas E, Pipi L, Mezzena S, Giannetti L. Use of orthodontic methods in the treatment of dental luxations: a scoping review. Dent J. 2021;9(2).

37. Rovira-Wilde A, Longridge N, McKernon S. Management of severe traumatic intrusion in the permanent dentition. BMJ Case Rep. 2021;14(3).
38. Bruszt P. Secondary eruption of teeth intruded into the maxilla by a blow. Oral Surg Oral Med Oral Pathol. 1958;11(2):146-9.

39. Colak I, Markovic D, Petrovic B, Peric T, Milenkovic A. A retrospective study of intrusive injuries in primary dentition. Dent Traumatol. 2009;25(6):605-10.

40. Carvalho V, Jacomo DR, Campos V. Frequency of intrusive luxation in deciduous teeth and its effects. Dent Traumatol. 2010;26(4):304-7.

41. Andreasen FM, Pedersen BV. Prognosis of luxated permanent teeth--the development of pulp necrosis. Endod Dent Traumatol. 1985;1(6):207-20.

42. Tsilingaridis G, Malmgren B, Andreasen JO, Malmgren O. Intrusive luxation of 60 permanent incisors: a retrospective study of treatment and outcome. Dent Traumatol. 2012;28(6):416-22.

43. Albers DD. Ankylosis of teeth in the developing dentition. Quintess Int. 1986;17(5):303-8.

44. Turley PK, Crawford LB, Carrington KW. Traumatically intruded teeth. Angle Orthod. 1987;57(3):234-44.

45. Tome W, Uematsu S, Yamashiro $\mathrm{T}$. Multidisciplinary treatment for a patient with traumatically intruded permanent canine and premolar. Aust Dent J. 2015;60(4):536-9.

46. Takahashi T, Takagi T, Moriyama K. Orthodontic treatment of a traumatically intruded tooth with ankylosis by traction after surgical luxation. Am J Orthod Dentofac Orthoped. 2005;127(2):233-41.

47. deSouza RF, Travess H, Newton T, Marchesan MA. Interventions for treating traumatised ankylosed permanent front teeth. Coch Databa System Rev. 2015;2015(12):007820.

48. Bauss O, Röhling J, Sadat-Khonsari R, Kiliaridis S. Influence of orthodontic intrusion on pulpal vitality of previously traumatized maxillary permanent incisors. Am J Orthod Dentofac Orthoped. 2008;134(1):12-7.

Cite this article as: Hifny SA, Hawsawi MA, Baraat AM, Bakhadlaq WF, Hakami HM, Alghamdi AA, et al. Orthodontic management of traumatized teeth: a literature review. Int J Community Med Public Health 2021;8:3138-42. 